\title{
Importancia de los ingresos públicos en la economía nicaragüense
}

\section{Importance of the public revenues in the nicaraguan economy}

\author{
Milton Ulises Mayrena Bellorín ${ }^{1}$
}

\section{RESUMEN}

Todos los países del mundo se ven en la necesidad de tener una organización administrativa bien definida para la administración de los ingresos públicos. Esta organización, es la encargada de planificar, organizar, dirigir y ejecutar todas las acciones encomendadas a cada nación desde las diferentes instituciones. Para lograrlo, se debe de contar con ingresos para que todo lo planificado se pueda ejecutar. En el presente escrito, se hace un análisis sobre los ingresos públicos, su importancia, y su implicancia en el desarrollo económico del país. Los tributos representan los principales ingresos para el estado, entre ellos se cuentan los impuestos, tasas y contribuciones especiales que todos los ciudadanos nicaragüenses de forma directa o indirecta contribuyen a dichos recaudos. Todos los ingresos recaudados son administrados el Ministerio de Hacienda y Crédito Público, siendo el responsable de distribuir las partidas presupuestarias a cada institución pública para la ejecución de sus planes anuales.

Palabras claves: ingresos públicos; tributos; impuestos; tasas y contribuciones especiales.

\begin{abstract}
All the countries around the world need to have an administrative organization well defined for the administration of the public revenues. This organization, is in charge of plan, organize, direct and execute all the actions states in each nation from different institutions. In order to achieve it, is necessary to count with the incomes to execute the plan. In this paper, there is an analysis of the public revenues, their importance and relevance in the development if the country. The taxes represent the main income for the state, including taxes, fees and special contributions made direct or indirectly by all the Nicaraguan citizens. All the incomes are administrated by the Ministry of Finance and Public Credit, being the responsible of distributing the budget to every public institution for the accomplishment of the annual plans.
\end{abstract}

Keywords: public revenues; taxes; fees; special taxes.

DOI: https://doi.org/10.5377/multiensayos.v3i6.9688

Recibido: 01 de diciembre de 2017

Aceptado: 17 de diciembre de 2017

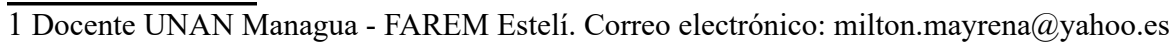




\section{INTRODUCCIÓN}

Los ingresos públicos son los recursos que capta el gobierno para realizar todas las actividades presupuestadas y por ende los pobladores de un país deben de cumplir con sus obligaciones tributarias para que se puedan desarrollar proyectos en cada una de la comunidades del territorio nacional.

"Solo los ingresos fiscales crecieron 15.5 por ciento, empujados por mayores recaudaciones en el Impuesto sobre la Renta (18.6 por ciento), el Impuesto al Valor Agregado (11.7 por ciento) y el Impuesto Selectivo al Consumo (15.1 por ciento)". "En términos absolutos, el Gobierno central acumuló hasta el séptimo mes del año 37,528.3 millones de córdobas en ingresos fiscales, 5,038 millones de córdobas más que en igual periodo del año pasado”. (Álvarez Hidalgo, 2017)

Los impuestos constituyen el principal componente de los ingresos públicos, otro componente de los mismos son los precios públicos establecidos por la utilización de instalaciones públicas; el gobierno también tiene otras vías de recursos públicos que son los procedentes de la venta de determinados activos, el Estado puede captar recursos mediante el endeudamiento.

\section{DESARROLLO}

Una de las principales características de los ingresos públicos es que debe ser siempre una suma de dinero, atendiendo esta característica no se consideran ingresos lo recaudado en especie, esto se da porque el estado debe captar dinero para poder hacer frente a las proyecciones presupuestarias que se realizan cada año. Los ingresos deben ser administrados por entes públicos, pues son estos los que realizan el control y ejecución de estos ingresos por medio de la realización de los proyectos sociales y los gastos de operación que tiene cada institución; siendo su principal objetivo financiar el gasto público.

El sistema tributario nacional está conformado por un conjunto de impuestos, tasas y contribuciones especiales, los cuales están distribuidos a nivel nacional, regional y municipal, teniendo además en cuenta el ámbito interno y externo; estos ingresos tributarios se recaudan en cualquier sistema de gobierno. "Los impuestos son tributos involuntarios que las personas y las empresas deben pagar a una entidad gubernamental (ya sea local, regional o nacional), con el fin de financiar al Estado y los servicios que el gobierno presta a los ciudadanos”. (Economía Simple, 2016)

Mencionando algunos ejemplos de los impuestos recaudados en nuestro país se encuentra el impuesto sobre la renta, este impuesto es uno de los más conocidos, recae sobre la capacidad contributiva en ingresos o utilidades, esto significa que se paga impuesto sobre la renta por la obtención de ingresos y de manera lógica va a pagar más impuesto el que obtiene mayores ingresos y menos impuestos el que menor ingreso tiene. 
Los ingresos gravados con el impuesto sobre la renta pueden provenir de ingresos de cualquier naturaleza, ya sea por sueldos o salarios, por actividades comerciales, profesionales o inclusive por obtener o ganarse un premio.

El Impuesto al Valor Agregado conocido como IVA es otro impuesto muy conocido por la población en general, este tipo de impuesto tiene como indicador la capacidad de consumo, esto significa que el poder adquisitivo es él que influye en este tipo de impuesto en otras palabras a mayor poder adquisitivo mayor impuesto de IVA tendrá que pagar al consumir o gozar de un producto o servicio.

Otras de las fuentes de ingresos es el tributo clasificado como tasa, a diferencia del impuesto, se caracteriza por que lo pagado ya sea al Estado o las municipalidades, conlleva a una contraprestación directa o individualizada a favor de quien lo pago: es decir, el ciudadano paga a cambio de recibir un servicio que puede individualizarse a favor de quien efectuó el pago.

"Las tasas son contraprestaciones económicas que hacen los usuarios de un servicio prestado por el estado. La tasa no es un impuesto, sino el pago que una persona realiza por la utilización de un servicio, por tanto, si el servicio no es utilizado, no existe la obligación de pagar por el". (Gerencie, 2017)

La contribución especial es otro tributo cuya obligación tiene como hecho generador beneficios derivados de la realización de obras públicas o de actividades estatales y cuyo producto no debe tener un destino ajeno a la financiación de las obras o las actividades que constituyan el presupuesto de la obligación.

"Las Contribuciones Especiales son los tributos cuyo hecho imponible consiste en la obtención de un beneficio o de un aumento de valor de los bienes de los particulares como consecuencia de la realización de obras públicas o de la ampliación de servicios públicos”. (Belgrano, 2013)

La redistribución de los ingresos consiste en llevar los recursos recaudados a las personas más necesitadas, esto se realiza por medio de gastos sociales, a través de programas de beneficio a sectores necesitados.

El estado desarrolla un conjunto de actividades económicas en favor de sus ciudadanos, para lo que necesita disponer de recursos con los que sufragar los gastos que conllevan estas necesidades, que cada vez adquieren mayor volumen, esto se debe a que cada día los ciudadanos adquieren nuevas necesidades y el estado debe ayudar a cubrirlas.

La actividad desarrollada por el sector público produce, como cualquier agente de producción, de recursos que genera su propia actividad económica; servicios que prestan el estado actualmente como transporte, suministro de agua, enseñanza, etc. generan ingresos que pueden cubrir, según el caso, la totalidad o solo una parte de los costos de producción de estos servicios. 
En la actualidad los gobiernos tienen como objetivo beneficiar a las personas con mayores necesidades económicas, es por esto que han desarrollado diferentes programas sociales para que estos lleguen principalmente a estos pobladores; debemos ser personas responsables con nuestras obligaciones tributarias y uno de estos es pagar siempre los diferentes impuestos, tasas y contribuciones especiales establecidas en el territorio nicaragüense.

"La proyección social del gobierno va hacia el interior, hacia las grandes mayorías, hacia los desposeídos. La proyección de construcción de casas es dirigida a todos los nicaragüenses, principalmente los sectores que habían sido olvidados y el Comandante Daniel está hablando de una proyección de 100 mil casas y si agregamos la atenciones en salud, más el servicio de agua potable que se está planificando en la área urbana y rural, todo esto constituye una proyección que está trazada y va a tener su cumplimiento". (Navarro, 2017)

La obtención de ingresos por parte del estado constituye un elemento fundamental para la existencia del mismo, desde que le permite sufragar su funcionamiento, y lo que es más importante, dar cumplimiento a los fines encaminados a obtener el bien común de todo el conjunto de la sociedad. Es por ello que en todos los estados existen sistemas encaminados a garantizar la recaudación de ingresos, los que abarcan desde el dictado en una normativa específica creada por el poder legislativo de la nación, dando atribuciones especiales a instituciones del estado para que ellas puedan recaudar esos fondos, en Nicaragua la institución pública responsable de este acto es la Dirección General de Ingresos - DGI. En este sentido, la percepción de los tributos constituye la parte más importante de los ingresos que forman la hacienda pública estatal.

Las instituciones públicas deber ser organizaciones responsables al momento de administrar y ejecutar los fondos asignados a su institución, esto con el objetivo de crear confianza en la población y no evadan los actos que generan ingresos en los gobiernos.

Se debe analizar y monitorear la obligación de las instituciones públicas y sus funcionarios de rendir cuentas, y la obligación general del estado de informar de manera veraz, oportuna, completa y responsable sobre todas sus actuaciones, y en particular, sobre aquellas relacionadas con la recaudación, gestión y control de impuestos.

Para generar control y confianza en los ingresos recaudados existen órganos de control, tanto interno como externo, llevando a cabo actividades de auditoría, en forma selectiva y apuntando a las áreas críticas.

Los administradores tributarios y los órganos superiores de fiscalización deben atender un conjunto de desafíos, entre ellos, en materia regulatoria o normativa de rendición de cuentas, no sólo para cumplir con el deber que les corresponde, sino también para incidir sobre la eficiencia del proceso de gestión de impuestos y sobre la equidad en el trato a los contribuyentes. 
El pago correcto de los impuestos representa un signo alentador de progreso dentro de las comunidades, los gobiernos deben estimular y mantener a través de una política de acercamiento y comprensión hacia los causantes. El pago de impuestos es una obligación, pero también un ingreso seguro y necesario para el estado, que éste tiene que garantizar en debida forma.

Si los impuestos son cubiertos normalidad, el fisco no enfrenta mayor dificultad, puesto que la finalidad buscada ha sido alcanzada. Sin embargo, el pago de impuestos da lugar a una serie de relaciones económicas entre los gobernados que pueden desembocar en un alza general del costo de vida. Cuando el legislador crea un impuesto, persigue básicamente gravar una determinada actividad productiva tratando de que el mismo incida sobre los rendimientos de un sector de la población.

Lo anterior hace pensar que el impuesto una vez constituido sigue un camino que va repercutiendo por todos los ámbitos de la economía nacional. Camino que lo lleva en diversos sentidos y que afecta todo tipo de relaciones industriales, comerciales y de consumo, frente a las cuales los principios constitucionales de equidad y proporcionalidad quedan relegados a un segundo término, provocándose así el principio de injusticia social que su desconocimiento implica.

Los gobiernos deben crear siempre campañas que incentiven y animen a las personas a cumplir con las obligaciones tributarias para que cada día el país se pueda desarrollar y que las personas de escasos recursos cubran la mayor parte de la necesidades esenciales para tener un mejor nivel de vida.

Cuando los pobladores de un país no pagan impuestos impide al gobierno destinar recursos suficientes para cubrir las necesidades de las personas más desposeídas y con escasos recursos económicos, por lo que es fundamental que cumplamos con esta obligación.

\section{CONCLUSIÓN}

La recaudación de los impuestos es de suma importancia para el país, ya que esto contribuye al progreso y estabilidad de nuestra nación, mejorando la economía, siendo la finalidad esencial del estado, el servir a la comunidad y promover la prosperidad de sus habitantes, todos los países contemplan en sus leyes la recaudación de los tributos, además de estar en constante supervisión y si es necesario la reforma de las mismas para beneficiar al estado y a la población.

\section{BIBLIOGRAFÍA}

Álvarez Hidalgo, W. (27 de 09 de 2017). Ingresos fiscales, municipales y donaciones dinamizan finanzas públicas de Nicaragua. Estado de Nicaragua con más ingresos, pág. 5.

Belgrano, M. (15 de 03 de 2013). Los recursos públicos. Recuperado el 24 de 11 de 2017, de 
Los recursos públicos: https://sites.google.com/site/elsistematributario/las-contribucionesespeciales-concepto

Economía Simple. (05 de 02 de 2016). Economía Simple. Recuperado el 23 de 11 de 2017, de Economía Simple Net: https://www.economiasimple.net/glosario/impuesto

Gerencie. (09 de 10 de 2017). Gerencie.com. Recuperado el 23 de 11 de 2017, de Gerencie.com: https:/www.gerencie.com/concepto-y-definicion-de-tasa.html

Navarro, W. (03 de 05 de 2017). El 19. Recuperado el 24 de 11 de 2017, de El 19: https://www. el19digital.com/articulos/ver/titulo:55827-programas-sociales-del-gobierno-sandinistason-proyectos-de-vida 